\title{
Analysis on the Evolution of Online Public Opinion on Sina Weibo Platform "Sino-US Trade Dispute"
}

\author{
Yang Wang ${ }^{1, *}$ \\ ${ }^{1}$ School of Government, Beijing Normal University, Beijing 100089, China \\ *Corresponding author. Email: 17301090619@163.com
}

\begin{abstract}
The gradual flattening of social media not only promotes the expression of citizens' power and will, but also forms socially influential online public opinions in public events of interest concern, or even leads to offline group gathering. Taking Sina Weibo as a research platform, this paper analyzes the development of online public opinion on Sino-US trade disputes from March 2018 to December 2019. The public participation degree, public opinion keyword extraction and Weibo public opinion sentiment analysis of popular Weibo Posts show that in front of issues related to national dignity and related interests, online public opinion can complete group identification and construction under appropriate guidance, and maintain a positive and healthy development trend.
\end{abstract}

Keywords: Online public opinion; Weibo; Sino-US trade disputes; Public opinion evolution;

\section{INTRODUCTION}

Historical institutionalism believes that any institution is created to solve problems in current economic and social development, and has stability at a certain point in history, and will not be easily changed by subsequent changes of the environment, and will exert a restrictive effect on the subsequent policy choices. Therefore, its continuation and change evidence should be found in the historical background and reality of its creation. Meanwhile, the formation and change of any institution is carried out in a specific specific cultural, historical, economic and social context. External pressures or crises, countries will adopt different policies to solve the problem. Expressing subjective opinions on social media or following opinion leaders to obtain relevant topic information has become the most popular activity of netizens on the Internet, and the network public opinion thus gathered has become a barometer to observe social trends [1], particularly on the topics concerned with state/national interest, which has the national cohesion force to a certain extent, but also fully exposed part of the group of irrational and extreme.Therefore, the analysis of the evolution of social media network public opinion is not only to achieve the healthy and stable role of the network environment, but more importantly to analyze the emotional sources and expectations of citizens through the monitoring of public opinion and data dynamics, so as to achieve a profound grasp of civic consciousness and appropriate guidance.This paper analyzes the evolution process of public opinion under the topic of "Sino-US trade dispute" with the help of Weibo platform, and captures the main emotional trends of the public when they participate in public affairs discussion with a view to "catch a glimpse", so as to provide reference for the monitoring of online public opinion on related issues in the future and the establishment of a benign public opinion ecology.

\section{LITERATURE REVIEW}

\subsection{The connotation and characteristics of online public opinion}

Public opinion is a reflection of the floating consciousness of the society, which is composed of "public + opinion" [2] and condensed into public opinion. As the shell of public opinion, public opinion is the synthesis of complex preferences expressed by a certain number of groups on important issues in a certain period [3].As the modern evolution of the term public opinion, network public opinion is the sum of the opinions that people hold on Public Affairs (social hot spots, focus issues) that they care about or are related to by relying on Internet space [4]. It is the direct stimulus and attitude object of public affairs and the aggregation of opinions with certain influence and tendency [5]. It can promote social process by virtue of the free expression space given by social media, and even open the policy window at the necessary time nodes.

Different from the traditional media, network public opinion is characterized by its uncontrollability.In the highly open and resource sharing space of the Internet, it is difficult to control the generation and dissemination of public opinion [6]. As a product of coding dimension, abstract dimension and diffusion dimension [7], online public opinion often shows some implicit characteristics, which can not be quickly identified and controlled at the beginning of the event.It will be multi-level derived due to 
the characteristics of netizens as the main body of "social people". It is also possible to combine with the spread and development of potential crisis to produce new variation, so as to accelerate the spread and even cause aftershocks of hot events.

In addition, the network public opinion relies on a certain focus of social events, constantly changing and developing in the emerging media, with a strong social spiritual force, which is a very rich and complex human spiritual phenomenon. Its inclusiveness is reflected in the comprehensiveness of content forms, while its complexity is reflected in the constant emergence of information waste in the interweaving of various emotions, intentions, attitudes and opinions.In this way, all kinds of cultural types, ideologies and moral norms have a foothold. Because of their differences, they float and collide in the Internet ocean, thus realizing the confrontation and emotional outburst of online diversified values.

\subsection{Formation and evolution of online public opinion}

Before the advent of the web2.0 era, the formation and development of public opinion and the feedback on its impact on the society all came from the collective action in reality. The interaction of group members' opinions (the external expression of attitudes, beliefs and emotions) will gradually form the dominant opinions, become the guide of group behavior [8], and finally contribute to the establishment of group norms. Figure 1 illustrates this process, starting with a real event, in which group members participate throughout the cycle, which may eventually lead to social action [9].

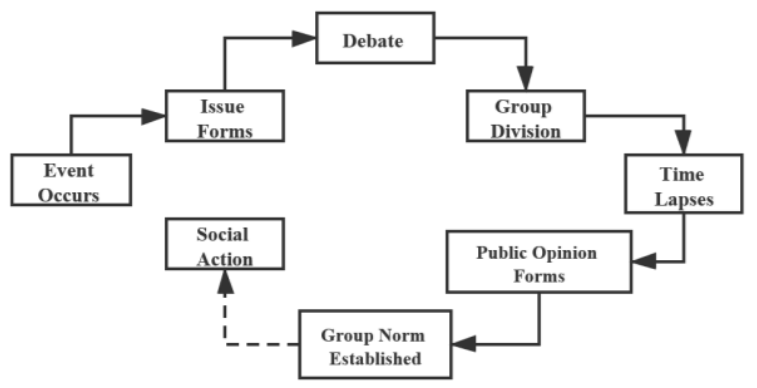

Figure 1 Group norm development process

Then, thanks to the immediacy and interactivity of the Internet, social platforms began to be favored by the public and gradually became an important place for public opinion gathering. Therefore, online public opinion is regarded as an important influencing factor on the strategy and agenda setting of the government or organization. It is the group members who generate the network public opinion that exert influence in essence, which reflects the game and collision of various public rights, including the right to speak and the public right to know, generated by different social strata and different interest groups.
Of course, in addition to the objective factors, the formation of online public opinion mainly comes from the event needs of netizens, including the need for respect and sense of belonging, as well as the high-level needs for self-worth realization. Therefore, it is necessary to realize self-expression, utilitarianism and emotional support with the help of network and social media platform [10]. From the micro perspective of information system, the behavior motivation of the public using the Internet can be divided into two types: information input (information acquisition) and information output (opinion expression) [11]. The stability of the network ecosystem can be maintained by balancing the two types. This also provides a theoretical construction for the public to continuously enter the Internet and participate in social discussions, which shows their pursuit and concern for spiritual needs in the context of rich material life.

Compared with news events in other fields, the public affairs related to the national economy and the people's livelihood, which reflect the social contradictions, are particularly concerned by netizens. Due to the influence of cultural background, cognitive level and interest position, there are some differences in attitudes and values of the public towards crisis events. Therefore, the complex information released by the public for crisis events will form a variety of emotions, and with the development of the crisis, the public will be in a state of ebb and flow in the whole network public opinion system, forming a diversified group view, which means that the online public opinion began to evolve, and because of multi-party interaction, it has a stage characteristic.According to the changing rules of public opinion itself, the development trend of public opinion will go through short or long periods [12]. The public's attention to crisis events is reflected in the wavy track from calm state to outbreak escalation and then to gradual calm down in the corresponding online public opinion.In addition, under the network environment, netizens are disturbed by massive information, and their persistence or toughness is low, which makes it easy to switch attention [13]. Coupled with special external resistance, public opinion will show a shrinking trend

\section{ANALYSIS ON THE EVOLUTION OF ONLINE PUBLIC OPINION - TAKING THE ISSUE OF "SINO-US TRADE DISPUTE" ON WEIBO AS AN EXAMPLE}

The media attributes and media value of Weibo are increasingly prominent. Its cohesion and loyalty make it rise out of the network public opinion field based on new media and become one of the most mainstream social media in China [14]. Weibo's platform of forwarding, comments, concerns, search of feature set constitute the unique dialogue structure of chain, ring, tree [15], its unique "information aggregation - point -- information fission" transmission mode [16], makes the propagation speed of hot topic geometric growth, and continuously 
penetrate into the vision of more users like "snowball". as an analysis platform for network public opinion.

Table 1 is an important basis for this paper to select Weibo

Table 1 The main features of Weibo

\begin{tabular}{|l|l|}
\hline \multicolumn{1}{|c|}{ Features [17] } & \multicolumn{1}{c|}{ Example } \\
\hline $\begin{array}{l}\text { Emotional sensitivity is complex, and the fermentation } \\
\text { path of public opinion is generated }\end{array}$ & $\begin{array}{l}337 \text { million users (China's Weibo } \\
\text { users in the first half of 2018) }\end{array}$ \\
\hline $\begin{array}{l}\text { The interest demand is clear and the network cluster } \\
\text { effect is obvious }\end{array}$ & $\begin{array}{l}\text { The interest demands can be realized } \\
\text { through the release of Weibo }\end{array}$ \\
\hline $\begin{array}{l}\text { Opinion leaders are coming out in large Numbers, } \\
\text { with higher public opinion heat and more far-reaching } \\
\text { influence }\end{array}$ & $\begin{array}{l}\text { Many influential people have entered } \\
\text { Weibo }\end{array}$ \\
\hline $\begin{array}{l}\text { Establish a new era of social media network opinion } \\
\text { Regulated cyberspace }\end{array}$ & Rerce \\
\hline
\end{tabular}

trade war has been upgraded again" has won 2,553

\subsection{Evolution analysis of online public opinion} on "Sino-US trade dispute"

\subsubsection{Public participation}

According to Weibo search statistics, as of October 31, 2019, the topic "New Proposal on the Trade War between China and the US" on Weibo has received 151,000 discussions and 280 million reads, while "the Sino-US discussions and 7.94 million reads. "Who is the winner of the Sino-US trade war?" Discussed by 601 , read by $3,294,000$. According to the number of forwarding, comments and likes of the top 50 posts related to "Sino-US trade dispute" from March 2018 to October 2019 (Table 2), the monthly trend of reposting, commenting and liking shows a consistent upward and downward trend. The "like" as a more intuitive expression of public opinion indicates the degree of active participation of netizens under the topic.

Table 2 The popularity of "Sino-US Trade Dispute" from March 2018 to October 2019 ranks the top 50 weibo public participation

\begin{tabular}{|c|c|c|c|c|c|c|c|}
\hline Date & Repost & Comments & Likes & Date & Repost & Comments & Likes \\
\hline Mar-18 & 90812 & 67194 & 225678 & Feb-19 & 4504 & 3271 & 15751 \\
\hline Apr-18 & 22088 & 25646 & 71859 & Mar-19 & 1137 & 699 & 2217 \\
\hline May-18 & 16127 & 14203 & 31406 & Apr-19 & 1369 & 760 & 1720 \\
\hline Jun-18 & 13709 & 21358 & 37083 & May-19 & 14619 & 15742 & 44777 \\
\hline Jul-18 & 32248 & 19390 & 36881 & Jun-19 & 22297 & 13463 & 122262 \\
\hline
\end{tabular}




\begin{tabular}{|c|c|c|c|c|c|c|c|}
\hline Aug-18 & 6845 & 10569 & 15256 & Jul-19 & 3892 & 3278 & 21612 \\
\hline Sep-18 & 10250 & 11562 & 16750 & Aug-19 & 18107 & 19574 & 143037 \\
\hline Oct-18 & 5407 & 5277 & 9027 & Sep-19 & 32302 & 12927 & 102241 \\
\hline Nov-18 & 4126 & 2542 & 6975 & Oct-19 & 5460 & 6803 & 36866 \\
\hline Dec-18 & 12000 & 4565 & 39446 & Nov-19 & 4126 & 2542 & 6975 \\
\hline Jan-19 & 791 & 1358 & 4226 & Dec-19 & 12000 & 4565 & 39446 \\
\hline
\end{tabular}

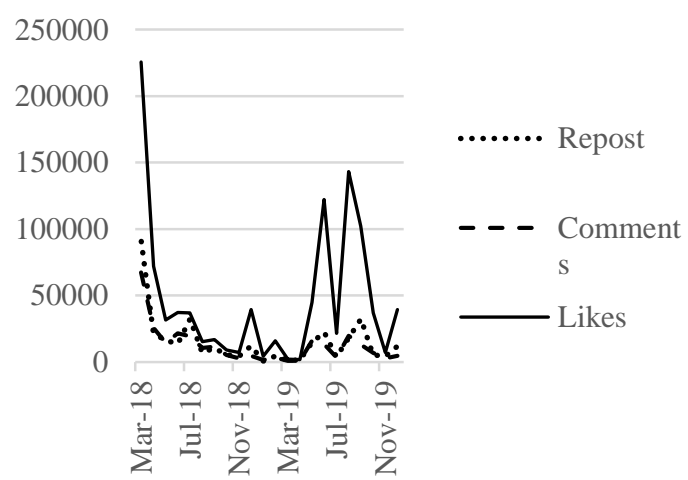

Figure 2 Line chart of top 50 Weibo public participation from March 2018 to October 2019

\subsubsection{Evolutionary stages}

From the above-mentioned line chart, it can be seen that the network public opinion presents "M" type characteristics. Affected by the trade friction between China and the US, public opinion shows certain fluctuations. By combining the broken line chart in Figure 2 , a more easily analyzed public opinion evolution map can be obtained (see Figure 3).

The online public opinion

(1) (2) (3)

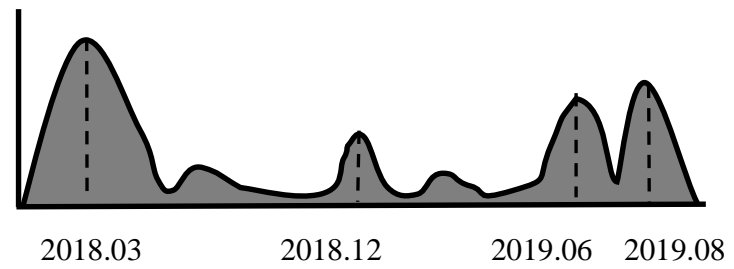

Figure 3 Evolution chart of "Sino-US Trade Dispute" public opinion

The whole development of public opinion can be divided into five stages, as shown in Figure 3. Stage(1) is the incubation period of Sino-US trade disputes. Since Trump took office, unfair trade behaviors against China have gradually revealed, and various hostile acts against China by Trump have attracted the attention of people from all walks of life. Although the public discussion on china-us relations already exists, it is still invisible because the focal issue that corresponds to it has not yet appeared [18].

From March 2018, the United States announced it would levy customs duties on imported steel and aluminium information and China's countermeasures to make the network public opinion reached the peak point, namely the stage(2), several government affairs Weibo microblogging platform was reported and clear the attitude held by the Chinese, many opinion leaders have also be reached for comment, lit the netizens strong patriotic emotion, realize the collision of speech and ferment.

Stage(3)is a cyclic period. After the rapid decline of public opinion from April 2018, public opinion shows a phased fluctuation, which is mainly affected by the Sino-US trade decision-making and the dramatic moves of the US side, and the public opinion nodes are closely overlapped with current affairs hot spots. The following are the key points of repeated public opinions: on May 20, 2018, the new round of trade negotiations ended, and China and the United States issued a joint statement declaring a truce. Both sides reached a consensus to seek win-win results and avoid the worst situation.The release of this official information means a turning point in the relaxation of Sino-US relations since the Sino-US trade war, thus greatly enhancing the sense of gain of the people and increasing public opinion. On June 15, the Sino-US trade war resumed. The United States insisted on tearing up the bilateral agreement and announced that it would impose a $25 \%$ tariff on US \$50 billion of Chinese imports, and met with China's tough counterattack. The dramatic performance of the United States makes the topic warm up again. While the national patriotic sentiment is high, it is also full of disgust and rejection of the capricious actions of the United States, resulting in a stable trend in May, June and July. However, after several rounds of games between China and the US, online public opinions began to decline, and netizens began to enter the fatigue period after receiving relevant information fully. There was no significant fluctuation from January to April in 2019, and netizens' attention was distracted due to the strong atmosphere of the New Year. 
By may 2019, online public opinion has come to stage (4), and there have been two periods of sharp rise, namely may and August, with a total of more than 100,000 likes.Based on the analysis of popular content in these two months, the reasons for these two sharp rises are as follows :(1) on May 22, 2019, Trish Regan, a female anchor of Fox Business channel, and Liu xin, a host of CGTN, made a cross-sea "fight" between Chinese and American female news anchors, which quickly became a hot topic on Weibo.(2) on August 24, 2019 , the US government announced the $\$ 550$ billion worth of all for China imports tariffs, the culmination of a trade war. At this point the United States and China into a climax, the relationship is also more and more complicated, a lot of opinion leaders has carried on the analysis summary of the events and the projections for China-US relations. At the same time, the adhesive situation for more than a year also had a certain impact on China's stock market and people's livelihood, which also caused doubts and concerns of netizens.
From September 2019, online public opinion gradually transitioned into the recession period. In the stage(5), the holding of National Day military parade diluted the heat of this topic. The approaching election of the US in 2020 also makes Trump show a loose stance on the trade issue with China, which makes the online public opinion decline naturally.

\subsection{Emotional analysis}

\subsubsection{Keyword analysis}

Emotion is an important motive constitutes public opinion, especially when it comes to the interests of the state issues, netizens have a higher degree of participation and sense of existence.Through the octopus collector to extract and collect the comments on the popular microblog of "Sino US trade dispute"from March 2018 to December 2019, and analyze them with BlueMC cloud chart tool, and select the following top 50 keywords (see Table 3 ).

Table 3"Sino-US Trade Disputes"Key word frequency table

\begin{tabular}{|c|c|c|c|c|c|}
\hline Key word & Frequency & Key word & Frequency & Key word & Frequency \\
\hline China & 575 & proud & 73 & $\begin{array}{l}\text { agriculture } \\
\text { products }\end{array}$ & 44 \\
\hline America & 346 & data & 71 & awesome & 44 \\
\hline support & 181 & economy & 70 & getting better & 43 \\
\hline come on & 175 & loss & 68 & the masses & 41 \\
\hline На На & 171 & Japan & 63 & uncertain & 41 \\
\hline motherland & 168 & negotiation & 63 & objective & 40 \\
\hline Trade war & 127 & history & 63 & not easy & 39 \\
\hline Develop & 118 & fist & 60 & Soviet Union & 39 \\
\hline try hard & 107 & suppress & 59 & both sides suffer & 38 \\
\hline wish & 106 & revival & 59 & pressure & 37 \\
\hline
\end{tabular}




\begin{tabular}{|c|c|c|c|c|c|}
\hline clap & 103 & benefit & 56 & tariff & 37 \\
\hline issue & 95 & rise & 55 & sanction & 36 \\
\hline powerful & 94 & protracted war & 54 & technology & 34 \\
\hline chance & 81 & opposition & 54 & feel at ease & 33 \\
\hline patriotism & 77 & unite & 51 & cost & 32 \\
\hline winner & 74 & pork & 47 & tragedy & 31 \\
\hline excited & 73 & education & 44 & & \\
\hline
\end{tabular}

From the above key words table, it can be seen that Sino-US relations have become the most concerned issue among netizens in Sino-US trade disputes. The words "support", "Ha Ha", "come on", "clap" and other words all indicate that most netizens hold a positive attitude towards China, and "unite", "wish","powerful"and "getting better" express the people's good wishes for the motherland's tenacious response to the U.S. trade stick, while the words "loss", "suppress", "opposition", "both sides suffer" and "sanction" all reveal the public's concern about a series of irrational actions of the United States against China. Secondly, "economy" has become the most beneficial vocabulary for netizens after the Sino-US trade round, including the words "pork" and "agriculture products" shown in the table, which are more intuitive problems in the economic field.

It can be seen from the emotional analysis of netizens' participation in the "Sino-US trade dispute" that the evolution of online public opinions presents the following three characteristics: first, the combination of suddenness and stress. Despite the long-standing trade frictions between China and the United States, US President Trump's trade stick to China also represents a clear starting point of Sino-US trade disputes, which makes the patriotic voice wave quickly occupy the Internet public opinion highland.The second is the expression of extreme and rational coexisting. Weibo breaks the power, social distance and discourse hierarchy in traditional communication, creating more possibilities for emotional disputes. If negative public opinion is allowed to develop, the context created by negative tone atmosphere will reduce or even offset the impact of positive public opinion.

\subsubsection{Representative user analysis}

Therefore, in the face of massive and fragmented nationalist sentiment and speech on many platforms, the official and mainstream media are also trying to build their own public opinion discourse system.Table 4 shows the government blogs with high activity under the topic of Sino-US trade disputes. Official blogs such as "People's Daily" and "People's Website" published and followed up the response of the Ministry of foreign affairs and the Ministry of Commerce of China to the US trade sanctions at the first time. Its authority can better guide the public opinion to the correct direction and create a rational and harmonious network nationalism.Third, strong patriotism. When it comes to issues of conflict and conflict between one country and another, the emotions of the people are always concentrated and quickly consolidated.National interests are above everything. Whether it is the official game of Sino-US trade disputes, or the heated discussion between the people's sensibility and rationality, these patriotic public opinions formed in Weibo are the desire and consciousness of Chinese people to enhance their national strength and freedom. They are formed in the long-term historical life of the Chinese nation, and they have a high recognition of the national culture, spirit and interests. In the face of the surging wave of Internet public opinion at this stage, the official blogs of mainstream media essentially formed a linkage and consensus with public opinion, which created good conditions for rapidly cooling extreme emotions and building a harmonious public opinion environment 
Table 4 Official Weibo representatives are releasing basic information about "Sino-US trade war"

\begin{tabular}{|c|c|c|c|}
\hline User name & User attribute(identity) & Number of fans & $\begin{array}{c}\text { Number of } \\
\text { blogs issued }\end{array}$ \\
\hline People's Daily & $\begin{array}{c}\text { Legal person Weibo of } \\
\text { People's Daily }\end{array}$ & 108227387 & 25 \\
\hline $\begin{array}{c}\text { People's } \\
\text { Network }\end{array}$ & $\begin{array}{c}\text { Legal person Weibo of } \\
\text { People's Network }\end{array}$ & 71087705 & 25 \\
\hline China Daily & Official Weibo of China Daily & 49112420 & 67 \\
\hline Globle Times & $\begin{array}{c}\text { Official Weibo of Globle } \\
\text { Times }\end{array}$ & 25463717 & 115 \\
\hline
\end{tabular}

Source: Weibo data statistics

During the rising discussion of Sino-US trade disputes, the surge in user activity and participation is largely due to opinion leaders' comments on and re-dissemination of mainstream media reports. With a large number of fans and subscriptions, opinion leaders rely on their sense of news and public spirit to promote the interaction of followers attracted by their special status, accumulated personality charm or reputation. Table 4 shows some big $\mathrm{V}$ users who are more active in the topic of "Sino-US Trade dispute". From March 2018 to December 2019, the number of Weibo posts has been more than $15^{1}$, with the number of followers ranging from 800,000 to 20 million. The appearance of opinion leaders on the Weibo platform has narrowed the public's attention to issues related to China-US trade, thus promoting the evolution of online public opinions and expression of emotions.

Table 5 Some opinion leaders released basic information on Weibo about "Sino-US trade war"

\begin{tabular}{|c|c|c|c|}
\hline User name & User attribute(identity) & Number of fans & $\begin{array}{l}\text { Number of } \\
\text { blogs issued }\end{array}$ \\
\hline Hu Xijin & Chief editor of Global Times & 20131433 & 69 \\
\hline Lang Xianping & Economist & 17272735 & 17 \\
\hline Juzuo Shaozhong & Famous military expert & 12228220 & 15 \\
\hline Tianjin guxia & $\begin{array}{l}\text { Private professional stock } \\
\text { investor }\end{array}$ & 6368660 & 115 \\
\hline Mei Xinyu & Scholar, columnist & 1252456 & 72 \\
\hline Lu Qiyuan & Famous financial Blogger & 1183001 & 35 \\
\hline Ren Zeping & $\begin{array}{l}\text { Chief economist, Evergrande } \\
\text { group }\end{array}$ & 814153 & 53 \\
\hline
\end{tabular}

Source: Weibo data statistics 
The network public opinion caused by "Sino-US trade dispute" is a network nationalism practice carried out by citizen groups, which reflects their positions and attitudes towards major political issues such as

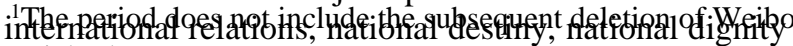
artickentebestsersetc. Its dominant public opinion style of nationalism is also the construction process of special self-identity and group identity as a "national community", which is conducive to enhancing the public's sense of national identity and cohesion.Although national politics, foreign policy orientation, strategic ideology orientation, and norms and scales of network public opinion also determine the strength of network nationalism voice [19].However, the evolution of network public opinion in this long period fully shows the rise of citizens' political participation, expression consciousness and network nationalism, which plays a positive role in building national security system and maintaining social harmony and stability.

\section{CONCLUSION}

With the advent of the Web2.0 era, social media represented by Weibo not only achieves the acquisition and dissemination of information, but also can rapidly aggregate public opinions to form group norms with identity. In addition, factors such as the interaction of diverse views, spatial appeal and topic publicity can help Weibo shape a unique split communication space, so as to influence the formation, evolution and trend of online public opinion. "Sino-US trade dispute", as an important hot event on Weibo from 2018 to 2019, is related to China's national security and social stability. In front of the major right and wrong related to national interests, netizens consciously formed a "virtual community" to safeguard the dignity of national interests. The public opinion evolution of the event indicates that the construction of national identity by the public has gradually become a spontaneous state, which reflects a strong sense of patriotism and a sense of civic responsibility that the national interests are above all else. Nowadays, Weibo is still responsible for the task of building national identity in the new era, and under the correct guidance of government Weibo and opinion leaders, the healthy development of network public opinion has been realized.In this era of multi situation and multi polarization, issues related to international relations occur from time to time. The orderly and positive public opinion of "Sino-US trade war" has created a good public opinion atmosphere for netizens to add national confidence and patriotic feelings.

\section{REFERENCES}

[1] Tian Hui, Ke Huixin.Analysis on the formation mode and regulation of public opinion under the network environment[J].Modern Communication(Journal of Communication University of China), 2010(01):40-45.

[2] Chen Lidan. Public opinion: A Study on the guidance of public opinion[M]. Shanghai: Shanghai Jiaotong University Press, 2012.

[3] Hem messy. Public Opinion[M]. Belmont: Wadsworth Publishing Company, 1970:24-25.

[4] Shi Bo Research on the internal evolution mechanism of network public opinion in public crisis events[J]. Journal of Intelligence,2010(4):41-45.

[5] $\mathrm{Xu}$ Xiaori.Research on emergency treatment of network public opinion events[J]. Journal of North China Electric Power University (SOCIAL SCIENCE EDITION),2007(1):89- 93.

[6] Tan Wei.The concept and characteristics of network public opinion[J]. Hunan Social Sciences,2003(5):188-190.

[7] Yi Chengzhi.Analysis on the evolution mechanism of network public opinion in Group Emergencies[J]. Journal of Intelligence,2011,30(12):6-12.

[8] Hart, D. and Scott, W. The organizational imperative[J]. Administration and Society,1997.

[9] Sturges, D.L., Carrell, B. J., Newsom, D. A., Barrera, M., (1990). Crisis Communication Management: Public Opinion Node and Its Relationship to Environmental Nimbus. SAM Advanced Management Journal, $56(3), 22-27$.

[10] Liu B F, Jin Y, Austin L L . The Tendency To Tell: Understanding Publics' Communicative Responses To Crisis Information Form and Source[J]. Journal of Public Relations Research, 2013, 25(1).

[11] Liu Chanjun,Li Mingde.Seeking the Fusion of Multiple Information Inputs and Rational Output-The Public Social Media Use and Their Influence on Social Governance[J].Journal of Intelligence,2019,38(05):131.

[12] Jiang Shenghong.The formation, development, status quo and guidance of public opinion on the Internet[J]. Theory Monthly,2008(04):34-36.

[13] Du Tao.Analysis on the evolution characteristics of network public opinion[J]. Journalism Lover,2005(1):37.

[14] Xie Yungeng,Rong Ting.Weibo public opinion generation and evolution mechanism and public opinion 
guidance strategy[J].Modern Communication(Journal of Communication University of China) ,2011(05):70-74.

[15] Xia Yuhe.The structure and mechanism of microblog interaction -- An Empirical Study Based on Sina Weibo[J]. Journalism\&Communication,2010,18(04):60-69+110-111.

[16] Wang Jing. Microblog resonates in network and reality[J]. New Media, 2010(004):64-65.

[17] Zhou Peiyuan,Jiang Jiebing. The characteristics and interaction of the public opinion field between the government and the people $[\mathrm{J}]$. Youth Journalist, 2012(24):32-33.

[18] Li Xiuli,Sun Xiangfei.On the formation and evolution mechanism of network public opinion in social media -Taking Wei Zexi incident as an example[J].News Tribune,2016(3):84-86. 